\title{
ANALISIS SALURAN PEMASARAN BUAH NAGA ORGANIK DI DESA JAMBEWANGI, KABUPATEN BANYUWANGI
}

\author{
$\underline{\text { Riza Rahimi Bachtiar'1, Abdul Holik }{ }^{2} \text {, dan Danang SWPJ Widakdo }}$ \\ 1,2,3)Program Studi Agribisnis, Politeknik Negeri Banyuwangi \\ Jl. Jember KM 13, Kec. Kabat, Kabupaten Banyuwangi, Jawa Timur, Indonesia \\ e-mail: 1)rizarahimi@poliwangi.ac.id
}

(Diterima 8 Agustus 2020/Revisi 8 Desember 2020/Disetujui 15 Desember 2020)

\begin{abstract}
Red dragon fruit is one of the strategic horticultural commodities that is growing rapidly in Banyuwangi because it has an exotic appearance and produces fruit that can be consumed. One area that cultivates organic red dragon fruit was Jambewangi. There were several problems in Jambewangi, such as farmers didn't know profit distribution and cost's share between marketing channels in organic red dragon fruit. The purpose of this study was to analyze the profit share and cost-share in Jambewangi. Determination of the research location used the purposive method and the method of determining the respondents used the snowball sampling method. The data used in this study are primary data and secondary data. The analysis used is the quantitative analysis used to measure the profit's share and cost's share. The results of the analysis can be concluded that the highest profit share value was found in channel 1 with $76.17 \%$ and the lowest cost share was also found in channel 1 with $23.83 \%$. This result showed that channel 1 was the most efficient organic red dragon fruit marketing channel, compared to other marketing channels.
\end{abstract}

Keywords: cost-share, organic red dragon fruit, profit share

\begin{abstract}
ABSTRAK
Buah naga merah merupakan salah satu komoditas holtikultura strategis yang berkembang pesat di Kabupaten Banyuwangi karena memiliki penampilan eksotis dan menghasilkan buah yang dapat dikonsumsi. Salah satu daerah yang membudidayakan buah naga merah organik adalah Desa Jambewangi. Terdapat beberapa permasalahan di Desa Jambewangi, yaitu petani belum mengetahui pembagian keuntungan dan biaya antar saluran lembaga tataniaga yang dimiliki. Tujuan penelitian ini adalah untuk menganalisis share keuntungan dan share biaya yang terdapat pada agribisnis buah naga organik di Desa Jambewangi. Penentuan lokasi penelitian menggunakan metode purposive dan metode penentuan responden menggunakan metode snowball sampling. Data yang digunakan dalam penelitian ini adalah data primer dan data sekunder. Analisis yang digunakan yaitu analisis kuantitatif digunakan untuk mengukur share keuntungan dan share biaya. Hasil analisis dapat disimpulkan bahwa nilai share keuntungan tertinggi terdapat pada saluran 1 yaitu sebesar $76,17 \%$ dan share biaya terendah juga terdapat pada saluran 1 yaitu sebesar $23,83 \%$. Hal ini menunjukkan bahwa saluran 1 merupakan saluran tataniaga buah naga merah organik yang paling efisien apabila dibandingkan dengan saluran tataniaga yang lain.
\end{abstract}

Kata kunci: buah naga merah organik, share keuntungan, share biaya

\section{PENDAHULUAN}

Buah naga merah merupakan salah satu komoditas holtikultura strategis yang berkembang pesat di Kabupaten Banyuwangi karena memiliki penampilan eksotis dan menghasilkan buah yang dapat dikonsumsi. Buah naga menjadi primadona baru bagi petani di wilayah Banyuwangi (Tiyas, et al., 2015). Kecamatan Sempu sebagai salah satu wilayah sentra penghasil buah naga memiliki luas wilayah 59,02 $\mathrm{km}^{2}$ dengan ketinggian 200-269 mdpl sehingga sesuai untuk budidaya buah naga (BPS, 2018). Keunggulan komparatif yang dimiliki oleh Kecamatan Sempu dibandingkan dengan wilayah sentra buah 
naga lain di Kabupaten Banyuwangi adalah menjadi sentra penghasil buah naga merah organik dan merupakan satu-satunya di Kabupaten Banyuwangi yang telah memiliki sertifikasi buah naga merah organik. Kecamatan Sempu memiliki 69 kelompok tani aktif yang tersebar di 7 desa. Salah satu desa yang menjadi sentra wilayah budidaya buah naga merah organik di Kecamatan Sempu terdapat pada Desa Jambewangi. Kelompok tani yang aktif berbudidaya buah naga merah organik di Desa Jambewangi adalah kelompok tani Pucang Sari.

Kegiatan tataniaga buah naga merah organik di Desa Jambewangi Kecamatan Sempu belum mampu menyampaikan hasil pertanian buah naga merah organik dari petani produsen kepada konsumen akhir dengan biaya yang murah sehingga selisih harga jual di tingkat petani produsen kepada konsumen akhir cenderung tinggi serta petani belum mampu mengetahui pembagian keuntungan dari masing-masing lembaga tataniaga yang terdapat pada kelembagaan tataniaga buah naga merah organik. Tataniaga produk pertanian selalu menjadi permasalahan mendasar bagi petani, oleh karena itu bagi petani yang telah memiliki produk usahatani dengan kuantitas dan kualitas yang baik tataniaga menjadi sangat penting (Widiastuti dan Harisudin, 2013).

Analisis mengenai saluran pemasaran dan efisien tataniaga merupakan hal yang sangat penting, hal ini dikemukakan oleh Amnimarlianda, et al (2018), dengan judul "Analisis Pemasaran dan Pendapatan Usahatani Semangka Kelompok Tani Ridho Lestari di Desa Tembokrejo Kecamatan Muncar Kabupaten Banyuwangi". Berdasarkan hasil penelitian diketahui bahwa terdapat 4 pola saluran pemasaran semangka yang melibatkan 7 lembaga pemasaran meliputi petani, tengkulak, pedagang besar, pedagang pengecer, konsumen, eksportir dan importir. Pola saluran pemasaran semangka meliputi : 1. Petani - pedagang - pedagang pengecer konsumen; 2. Petani - tengkulak - pedagang pedagang pengecer - konsumen; 3. Petani tengkulak - pedagang pengecer - konsumen;
4. Petani - eksportir - importir. Pemasaran semangka ekspor memiliki nilai marjin tertinggi dan tidak efisien sedangkan saluran pemasaran semangka non ekspor adalah efisien. Penelitian ini dapat memberikan informasi mengenai produk yang dapat memberikan keuntungan lebih tinggi.

Desa Jambewangi merupakan salah satu daerah yang memiliki potensi buah naga merah organik. Hal ini menyebabkan dibutuhkan suatu analisis share keuntungan dan share biaya yang bertujuan untuk menganalisis biaya yang paling efisien dan keuntungan yang paling tinggi sehingga diharapkan mampu memberikan rekomendasi kepada lembaga tataniaga agar memilih biaya dan keuntungan yang paling efisien.

\section{METODE}

\section{PENGUMPULAN DATA DAN ANALISIS}

Teknik pengumpulan data dimulai dari menentukan responden. Responden awal dalam penelitian ini adalah petani di Kecamatan Sempu. Teknik penentuan responden dilakukan menggunakan metode snowball sampling. Snowball sampling adalah teknik pengambilan sampel sumber data yang pada awalnya jumlahnya sedikit tersebut belum mampu memberikan data yang lengkap, maka harus mencari orang lain yang dapat digunakan sebagai sumber data (Muhajir, 1996). Penentuan sampel secara snowball sampling dalam penelitian ini pertama-tama menggunakan responden petani buah naga merah organik dan lembaga tataniaga buah naga merah organik yang terkait. Pengumpulan data dilakukan dengan cara survey dan pengamatan langsung dengan mewawancarai semua responden yang terlibat menggunakan kuesioner dan merekam seluruh hasil wawancara. Penelitian ini melibatkan petani buah naga merah organik yang berbudidaya buah naga merah organik di Desa Jambewangi Kecamatan Sempu. Luasan lahan budidaya buah naga merah organik di Desa Jambewangi yang telah tersertifikasi seluas 2 ha yang dimiliki 
oleh 2 orang petani dan 1 orang petani yang telah registrasi sertifikasi organik.

Analisis yang digunakan adalah analisis share keuntungan dan share biaya digunakan untuk mengetahui biaya dan keuntungan dari masing-masing lembaga tataniaga. Keuntungan dan biaya dari masing-masing lembaga tataniaga dinyatakan dalam satuan rupiah per kilogram, namun share keuntungan dan share biaya dinyatakan dalam satuan prosentase (Amnimarlianda, 2018). Suherman, et al (2011) menyatakan bahwa untuk mengetahui nilai share keuntungan dan share biaya dapat digunakan rumus:

$$
\begin{gathered}
\text { Share Biaya }(\mathrm{Bi})=\frac{B i}{P r} \times 100 \% \\
\text { Share Keuntungan }(\mathrm{Ki})=\frac{K i}{P r} \times 100 \%
\end{gathered}
$$

Keterangan:

Bi = Biaya tataniaga yang dikeluarkan oleh lembaga tataniaga ke-i

$\mathrm{Ki}=$ Keuntungan tataniaga yang didapatkan oleh lembaga tataniaga ke-i

$\operatorname{Pr}=$ Harga di tingkat konsumen

Biaya tataniaga didapatkan dari penjumlahan seluruh biaya yang dikeluarkan oleh lembaga tataniaga (petani, pedagang, atau konsumen). Contoh biaya tataniaga adalah biaya pemasaran, biaya transportasi, biaya kemasan, dan lain sebagainya. Sedangkan keutungan didapatkan dari pendapatan yang didapatkan oleh lembaga tataniaga dari hasil penjualan produk yang telah dikurangi dengan biaya tataniaga yang dikeluarkan.

Kriteria: Purwono, et al (2014) menyatakan bahwa efisiensi tataniaga dapat tercapai apabila sebaran keuntungan merata bagi seluruh lembaga tataniaga. Jumiati, et al (2013) menyatakan bahwa: Apabila perbandingan share keuntungan dari masing-masing lembaga pemasaran yang terlibat dalam proses pemasaran merata, maka sistem pemasarannya dikatakan efisien.
Apabila perbandingan share keuntungan dengan biaya pemasaran masing-masing lembaga pemasaran yang terlibat dalam proses pemasaran merata dan cukup logis, maka sistem pemasarannya dikatakan efisien.

\section{HASIL DAN PEMBAHASAN}

Berdasarkan hasil penelitian terdapat 7 saluran tataniaga buah naga merah organik Desa Jambewangi, masing-masing saluran tataniaga memiliki nilai share keuntungan dan share biaya yang berbeda. Berikut adalah saluran tataniaga buah naga merah organik di Desa Jambewangi :

Agribisnis buah naga organik di Desa Jambewangi terdiri dari 7 saluran tataniaga, antara lain:

1. Petani - pedagang pengumpul desa pedagang pengumpul kabupaten supermarket - konsumen.

2. Petani - pedagang pengumpul kabupaten - supermarket - konsumen.

3. Petani - pedagang pengumpul desa pedagang pengecer - konsumen.

4. Petani - pedagang pengecer - konsumen.

5. Petani - pedagang pengumpul kecamatan - pedagang pengecer - konsumen.

6. Petani - pedagang pengumpul kecamatan - konsumen.

7. Petani - konsumen.

Rekapitulasi nilai share keuntungan dan share biaya dari 7 saluran tataniaga buah naga merah organik Desa Jambewangi dapat dilihat pada Tabel 1.

Tabel 1. Rekapitulasi Share Keuntungan dan Share Biaya

\begin{tabular}{lcc}
\hline Saluran Tataniaga & $\begin{array}{c}\text { Share } \\
\text { Kuntungan } \\
\text { (SKi) }\end{array}$ & $\begin{array}{c}\text { Share } \\
\text { Biaya } \\
\text { (SBi) }\end{array}$ \\
\hline Saluran Tataniaga 1 & $76,17 \%$ & $23,83 \%$ \\
Saluran Tataniaga 2 & $74,38 \%$ & $25,63 \%$ \\
Saluran Tataniaga 3 & $68,80 \%$ & $31,21 \%$ \\
Saluran Tataniaga 4 & $70,17 \%$ & $29,83 \%$ \\
Saluran Tataniaga 5 & $53,29 \%$ & $46,71 \%$ \\
Saluran Tataniaga 6 & $54,79 \%$ & $45,21 \%$ \\
Saluran Tataniaga 7 & $70,50 \%$ & $29,50 \%$ \\
\hline Sumber: Data Primer Diolah, 2019
\end{tabular}


Tabel 1 menunjukkan nilai share keuntungan dan share biaya buah naga merah organik Desa Jambewangi secara keseluruhan. Nilai share keuntungan terbesar terdapat pada saluran tataniaga 1 sebesar $76,17 \%$ dan nilai share biaya terkecil terdapat pada saluran tataniaga 1 sebesar $23,83 \%$

Tabel 1 juga menunjukkan bahwa nilai keuntungan pada 7 saluran tataniaga buah naga merah organik lebih besar dibandingkan dengan nilai biaya yang dikeluarkan lembaga tataniaga. Share keuntungan dan share biaya pada masing-masing saluran antara lain:

- Share keuntungan dan share biaya saluran 1 masing-masing sebesar $76,17 \%$ dan $23,83 \%$.

- Share keuntungan dan share biaya saluran 2 masing-masing sebesar $74,43 \%$ dan $25,58 \%$.

- Share keuntungan dan share biaya saluran 3 masing-masing sebesar $68,80 \%$ dan $31,21 \%$.

- Share keuntungan dan share biaya saluran 4 masing-masing sebesar 70,17\% dan 29,83\%.

- Share keuntungan dan share biaya saluran 5 masing-masing sebesar 53,29\% dan 46,71\%.

- Share keuntungan dan share biaya saluran 6 masing-masing sebesar 54,79\% dan 45,21\%.

- Share keuntungan dan share biaya saluran 7 masing-masing sebesar 70,50\% dan 29,50\%.

Masing-masing lembaga tataniaga yang terlibat dalam tataniaga mengambil keuntungan dan mengeluarkan biaya yang berbeda selama proses tataniaga berjalan. Terdapat 7 saluran dalam tataniaga buah naga merah organik. Share keuntungan menunjukkan pembagian keuntungan yang didapatkan oleh masing-masing lembaga tataniaga di dalam saluran tataniaga buah naga merah organik.

Berdasarkan Tabel 1 dapat diilihat bahwa share keuntungan tertinggi terjadi pada saliran 1 yaitu 76,17\%, hal ini menunjukkan bahwa dari ketujuh saluran, saluran 1 yang memberikan pembagian keuntungan paling besar kepada seluruh lembaga tataniaga yang terlibat. Sedangkan nilai share keuntungan paling rendah terdapat pada saluran 5 yaitu 53,29 . Hal ini menunjukkan pembagian keuntungan kepada lembaga tataniaga yang terlibat di saluran 5 kurang merata apabila dibandingkan dengan saluran tataniaga yang lain. Pembagian keuntungan yang merata menunjukkan saluran tataniaga yang efisien. Sehingga dapat dikatakan bahwa saluran 1 merupakan saluran tataniaga yang efisien. Perhitungan mengenai share keuntungan pada saluran tataniaga 1 dapat dilihat pada Tabel 2.

Tabel 2. Share Keuntungan Saluran Tataniaga 1

\begin{tabular}{|c|c|c|c|}
\hline $\begin{array}{l}\text { Lembaga } \\
\text { Tataniaga }\end{array}$ & Uraian & $\begin{array}{l}\text { Harga } \\
\text { (Rp/Kg) }\end{array}$ & $\frac{K i^{S K i}}{P r} x 100 \%$ \\
\hline \multirow{8}{*}{$\begin{array}{l}\text { Pedagang } \\
\text { pengumpul } \\
\text { kabupaten }\end{array}$} & Harga Beli & 30.000 & \multirow{8}{*}{$\begin{array}{l}\frac{5.250}{40.000} \times 100 \% \\
=13,13 \%\end{array}$} \\
\hline & Transportasi & 250 & \\
\hline & Tenaga Kerja & 500 & \\
\hline & Pengemasan & - & \\
\hline & Biaya Tataniaga & 750 & \\
\hline & Harga Jual & 36.000 & \\
\hline & Keuntungan & 5.250 & \\
\hline & Marjin Tataniaga & 6.000 & \\
\hline \multirow[t]{10}{*}{ Supermarket } & Harga Beli & 36.000 & \multirow{13}{*}{$\begin{array}{l}\frac{2.225}{40.000} \times 100 \% \\
=5,56 \%\end{array}$} \\
\hline & Transportasi & 200 & \\
\hline & Tenaga Kerja & 700 & \\
\hline & Pengemasan & 50 & \\
\hline & Penyusutan & 775 & \\
\hline & Penyimpanan & 50 & \\
\hline & Biaya Tataniaga & 1.775 & \\
\hline & Harga Jual & 40.000 & \\
\hline & Keuntungan & 2.225 & \\
\hline & Marjin Tataniaga & 4.000 & \\
\hline \multirow[t]{4}{*}{ Konsumen } & Harga Beli & 40.000 & \\
\hline & Total Biaya & 9.533 & \\
\hline & Total Keuntungan & 30.467 & \\
\hline & TOTAL & & $76,17 \%$ \\
\hline
\end{tabular}

Perhitungan share biaya pada Saluran Tataniaga 1 dapat dilihat pada Tabel 3. Share biaya menunjukkan pembagian biaya kepada masing-masing lembaga tataniaga yang terlibat di dalam saluran tataniaga. Berdasarkan nilai pada Tabel 1, dapat diketahui bahwa saluran 1 menunjukkan share biaya yang terendah apabila dibandingkan dengan saluran tataniaga yang lainnya yaitu 23,83\%. Hal ini menunjukkan bahwa pembagian biaya yang dikeluarkan oleh saluran 1 lebih sedikit dibandingkan dengan saluran tataniaga yang lain. Pembagian biaya yang relative rendah menunjukkan saluran tataniaga yang efisien apabila dibandingkan dengan saluran tataniaga yang lain. 
Tabel 3. Share Biaya pada Saluran Tataniaga 1

\begin{tabular}{|c|c|c|c|}
\hline $\begin{array}{l}\text { Lembaga } \\
\text { Tataniaga }\end{array}$ & Uraian & $\begin{array}{c}\text { Harga } \\
\text { (Rp/Kg) }\end{array}$ & $\begin{array}{l}\text { SBi } \\
\frac{B r}{P r} x 100 \%\end{array}$ \\
\hline \multirow{8}{*}{$\begin{array}{l}\text { Pedagang } \\
\text { pengumpul } \\
\text { kabupaten }\end{array}$} & Harga Beli & 30.000 & \multirow{8}{*}{$\begin{array}{l}\frac{750}{40.000} \times 100 \% \\
=1,88 \%\end{array}$} \\
\hline & Transportasi & 250 & \\
\hline & Tenaga Kerja & 500 & \\
\hline & Pengemasan & - & \\
\hline & Biaya Tataniaga & 750 & \\
\hline & Harga Jual & 36.000 & \\
\hline & Keuntungan & 5.250 & \\
\hline & Marjin Tataniaga & 6.000 & \\
\hline \multirow[t]{10}{*}{ Supermarket } & Harga Beli & 36.000 & \multirow{13}{*}{$\begin{array}{l}\frac{1.775}{40.000} \times 100 \% \\
=4,44 \%\end{array}$} \\
\hline & Transportasi & 200 & \\
\hline & Tenaga Kerja & 700 & \\
\hline & Pengemasan & 50 & \\
\hline & Penyusutan & 775 & \\
\hline & Penyimpanan & 50 & \\
\hline & Biaya Tataniaga & 1.775 & \\
\hline & Harga Jual & 40.000 & \\
\hline & Keuntungan & 2.225 & \\
\hline & Marjin Tataniaga & 4.000 & \\
\hline \multirow[t]{4}{*}{ Konsumen } & Harga Beli & 40.000 & \\
\hline & Total Biaya & 9.533 & \\
\hline & Total Keuntungan & 30.467 & \\
\hline & TOTAL & & $23.83 \%$ \\
\hline
\end{tabular}

\section{KESIMPULAN DAN SARAN}

\section{KESIMPULAN}

1. Share keuntungan tertinggi terdapat pada saluran tataniaga 1 sebesar 76,17\% sedangkan nilai share biaya terendah juga terdapat pada saluran tataniaga 1 sebesar 23,83\%. Hal ini menunjukkan bahwa saluran 1 merupakan saluran yang paling efisien apabila dibandingkan dengan saluran tataniaga yang lain.

2. Masing-masing lembaga tataniaga yang terlibat dalam tataniaga mengambil keuntungan dan mengeluarkan biaya yang berbeda selama proses tataniaga berjalan.

\section{SARAN}

1. Seluruh lembaga tataniaga yang terdapat pada sistem agribisnis buah naga organik di Desa Jambewangi sebaiknya dapat berkomunikasi dan bekerja sama dengan baik, sehingga keuntungan dan biaya yang ditanggung dalam proses tataniaga dapat menjadi lebih efisien.

2. Petani disarankan untuk memelihara saluran tataniaga yang telah efisien dan membuat kontrak kerjasama tertulis terkait penanggungan risiko penyusutan produk buah naga merah organik agar tidak hanya merugikan petani.

\section{DAFTAR PUSTAKA}

Amnimarlianda, B. I., Syafii, I., Supriono, A. 2018. Analisis Pemasaran dan Pendapatan Usahatani Semangka Kelompok Tani Ridho Lestari di Desa Tembokrejo Kecamatan Muncar Kabupaten Banyuwangi. JSEP. 11 (2): 4654 .

Badan Pusat Statistik. 2018. Banyuwangi Dalam Angka. Badan Pusat Statistik Kabupaten Banyuwangi.

Hardjadinata. 2010. Budidaya Buah Naga Super Red Secara Organik. Jakarta : Penebar Swadaya.

Jumiati, E, Darwanto, D.H, Hartono,S; Masyhuri. 2013. Analisis Saluran Pemasaran dan Marjin Pemasaran Kelapa Dalam di Daerah Perbatasan Kalimantan Timur. Jurnal Agrifor.XII (1):1-21.

Muhajir, Noeng. 1996. Metode Penelitian Kualitatif. Yogykarta : Rake Serasia.

Purwono, J., Sugyaningsih, S., Fajriah, N. 2014. Analisis Tataniaga Bunga Krisan di Kecamatan Cugenang Kabupaten Cianjur. Jurnal Neo-Bis. 8 (2): 132- 146.

Purwono, J., Sugyaningsih, S., Priambudi, A. 2013. Analisis Tataniaga Beras di Kecamatan Rogojampi Kabupaten Banyuwangi. Jurnal Neo-Bis. 7 (2): 2-15.

Puspitasari, T. 2017. Analisis Keberlanjutan Good Agriculture Practice (GAP) Usahatani Buah Naga di Desa Jambewangi Kecamatan Sempu Kabupaten Banyuwangi. [skripsi]. Jember: Universitas Jember.

Sugiyono. 2017. Metode Penelitian Kuantitatif, Kualitatif, RED. Bandung: Alfabeta.

Suherman, T., Fauziyah, E., Hasan, F. 2011. Analisis Pemasaran Garam Rakyat (Studi Kasus Desa Kertasada, Kecamatan Kalianget, Kabupaten Sumenep). Embryo. 8 (2): 73-81. 
Tiyas, A., Putra, I.G.S.A., dan Dewi, I.A.L. 2015. Analisis Finansial Usahatani Buah Naga Super Merah (Hylocereuus costaricensis) (Studi Kasus Di Kelompok Tani Berkah Desa Sambirejo Kecamatan Bangorejo Kabupaten Banyuwangi). EJurnal Agribisnis dan Agrowisata. 4 (5): 402411.

Utami, P dan Budiningsih, S. 2007. Analisis Efisiensi Saluran Pemasaran Salak Pondoh (Studi Kasus di Desa Sigaluh Kecamatan Banjarnegara). Agritech. 9 (10): 94-108.

Widiastuti dan Harisudin. 2013. Saluran dan Marjin Pemasaran Jagung di Kabupaten Grobogan. SEPA. 9 (2): 231-240. 